\title{
ANTI-RASISME DALAM NOVEL PERJALANAN BURMESE DAYS KARYA GEORGE ORWELL
}

\author{
Fitrilya Anjarsari
}

S2 Ilmu Sastra UGM

Email: fitrilyaanjarsari@gmail.com

\begin{abstract}
Abstrak
Penelitian ini bertujuan untuk mengkaji peranan Orwell dalam menuliskan tulisan (laporan) perjalanan. Adanya pergeseran baik dari segi bentuk, isi, maupun fungsi dari tulisan perjalanan menggiring peneliti untuk membongkar posisi Orwell dalam laporan perjalanan. Pendekatan penelitian ini menggunakan konsep negosiasi, self and othering milik Carl Thompson, sehingga ditemukan bagaimana posisi dan peranan Orwell dalam melihat sekaligus menanggapi situasi politik apartheid (rasis) di Burma yang juga secara langsung akan mengungkap kecenderungan pengaruh yang ada di dalam diri Orwell.
\end{abstract}

Kata kunci: Rasisme, Travel Writing, Negosiasi, Self and Othering.

\section{Abstract}

This research is aimed to analyze Orwell's role in writing a travel writing. Shifting in type, main story, and function of a travel writing leads the researcher to reveal Orwell's position in it. Approach applied in this research is the concept of negotiation; self and othering by Carl Thompson. It will help the researcher to find out the position and role of Orwell in seeing and responding to apartheid political situation (racism) in Burma. This will also directly reveal the tendential influences existing in Orwell himself.

Keywords: Racism, Travel Writing, Negotiation, Self and Othering

\section{Pendahuluan}

Travel writing atau laporan perjalanan merupakan satu hal yang baru ketika hal tersebut dikatakan sebagai sebuah karya sastra. Seperti catatan pada umumnya, travel writing hanya sebuah catatan biasa yang objektif pada setiap laporannya, namun hal tersebut dapat diperdebatkan ketika bahasa yang digunakan dalam pemaparan sebuah laporan adalah bahasa subjektif yang ekspresif layaknya bahasa sastra. Oleh karena itu, pengkajian terhadap sebuah laporan perjalanan dari segi kesusastraan dapat tetap dilakukan melihat dari bentuk bahasa yang digunakan.

Perjalanan merupakan kegiatan di mana ada gerakan perpindahan dari satu tempat ke tempat yang lain. Dalam perpindahan tersebut, tentu subjek akan bertemu dengan hal-hal biasa atau pun hal yang sama sekali baru bagi dirinya. Adapun pertemuannya tersebut dituliskan dalam bentuk sebuah catatan. Carl Thompson mendefinisikan sebuah perjalanan yakni travel sebagai "an encounter between self and other that's brought about by movement throught and space", dan laporan perjalanan sebagai "is at some level a record or product of this encounter, and of the negotiation between similarity and difference that it entailed" (2011: 10). Hal yang perlu diingat dari pengertian travel writing menurut Thompson, yakni pertemuan antara selfdan otheryang kemudian menimbulkan negosiasi yang berimplikasi pada keduanya sebagai konsekuensi sebuah perjalanan.

Sebuah laporan perjalanan tidak hanya berisi semua gambaran pengalaman penulis atas perjalanannya. Dalam penulisan laporan perjalanan, hanya pengalaman yang dianggap baru bagi penulis yang dituliskan sebagai laporan. Ada penyeleksian yang ketat dilakukan oleh penulis dalam menuliskan laporannya tersebut termasuk anggapan subjektifnya. Menurut Thompson, hal tersebut merupakan proses transliterasi dari travel experience ke dalam travel text (2011: 62). Adapun hal-hal yang dimuat dalam laporan perjalanan ditentukan oleh tujuan perjalanan itu dilakukan. Thompson (2011: 104) mengatakan "the chief duty prescribed 
for almost all travel writers before the late $18^{\text {th }}$ century was that they bring back useful knowledge." Oleh karenanya, pada saat itu penulis melakukan proses seleksi dan hanya memuat apa-apa yang dianggap sebagai ilmu pengetahuan pada saat itu, sehingga laporan perjalanan menuntut satu nilai validitas yang pasti. Tradisi penulisan laporan perjalanan seperti ini seakan menyajikan satu pengalaman baru tersendiri kepada pembacanya yang tentunya secara langsung membentuk satu pandangan terhadap suatu hal yang baru baginya. Hal ini berdampak munculnya stigma-stigma tertentu pada pembaca terhadap suatu tempat/wilayah maupun manusianya yang disusun secara masif, terstruktur, dan sistematis oleh penulis dan pemerintah waktu itu .

Seiring bertumbuhnya jalur transportasi yang memudahkan manusia untuk melakukan perjalanan, maka semakin banyak orang yang melakukan perjalanan ke tempat-tempat baru yang belum pernah dikunjungi. Untuk itu tulisan perjalanan pun mengalami perkembangan, dan validitas tidak lagi menjadi masalah yang berarti dikarenakan pembaca sudah mulai membaca tulisan perjalanan sebagai sebuah hiburan dimana mereka bisa diajak melihat tempat yang belum pernah dikunjungi melalui narasi penulis. Perubahan ini mengakibatkan penulis memiliki ruang gerak yang lebih bebas untuk berekspresi di dalam tulisan perjalanan. Penulis biasanya juga membuat tulisan perjalanan seperti karya sastra dan bukan lagi seperti bentuk laporan perjalanan, contohnya tulisan George Orwell yang akan dibahas ini merupakan sebuah tulisan perjalanan yang dimasukkan ke dalam karya sastra perjalanan. Thompson melihat lebih jauh lagi karakteristik tulisan perjalanan era modern ini sebagai berikut:

"the modern travel book is usually more overtly autobiographical and more self-consciously literary than most of the travelogues from different era. This emphasis on autobiography and literariness causes the modern travel book's agenda and its generic contract with the reader, to be subtly but significantly different from that which operates in other forms of travel writing. In a sense, it ceases to matter as much whether the information we are being given is strictly true. Instead, readers understand that they are reading for the insights they will gain into the writer's distinctive sensibility, and for the pleasure they will gain from an equally individual literary style" (Thompson, 2011:88).

Dengan demikian dapat dikatakan bahwa pada tulisan perjalanan era modern, ideologi penulis bisa dilihat melalui bagaimana dia menceritakan perjalanannya. Hal ini dikarenakan pada masa itu, tulisan perjalanan juga dijadikan penulisnya untuk mengutarakan kritik atas kondisi sosial politik yang ada pada waktu dan tempat dia melakukan perjalanan. "in 1930s the travelogues seemed to enable more direct engagement with worldly affairs and with politics than was possible in the traditional literary genres" (Thompson, 2011:58).

Tulisan perjalanan era modern dikatakan sebagai sebuah tulisan yang memiliki keterkaitan khusus dengan kondisi politik yang ada di dunia saat itu. Hal ini tentu saja akan memuat bagaimana komentar atau pandangan penulis terhadap situasi sosial dan politik di tempat yang dia kunjungi. Pada paper ini akan dibahas karya George Orwell yang berjudul Burmese Days yang terbit pada tahun 1934 yang menceritakan mengenai kehidupan dia selama menjadi British officer di Burma. Di dalam karyanya ini Orwell memperlihatkan bagaimana hubungannya dengan sesama British officer juga dengan native people dan seorang India. Orwell memperlihatkan bagaimana kawan-kawannya yang sesama dari Inggris melakukan rasisme terhadap penduduk asli juga orang-orang oriental di Burma. Rasisme sendiri dikatakan oleh Newman (2012:405) sebagai belief that buman are subdivided into distinct group that are different in their social behavior and innate capacities and that can be ranked as superior or inferior in the matter of race. Hal itu terjadi kepada orangorang Inggris yang berada di Burma. Mereka merasa bahwa dari segi ras, mereka adalah yang superior dan orang-orang oriental merupakan inferior. Orwell sendiri yang diwakili oleh 
tokoh Flory di dalam novel ini menyuarakan ketidaksetujuannya terhadap apa yang dilakukan rekan-rekannya itu.

Dari pembacaan sekilas, Burmese Days menyiratkan paham ideologi humanisme universal yang dianut oleh Orwell. Tindakannya membela penduduk asli terhadap politik apartheid (rasis) yang terjadi di Burma. Kesimpulan awal yang muncul dari pembacaan sekilas tersebut menjadi alasan peneliti untuk membongkar latar belakang Orwell dari segala tindakannya. Hal yang akan membantu untuk menemukan ideologi Orwell dilihat dari bagaimana cara dia menempatkan dirinya di dalam cerita sebagai 'self dan siapa saja yang dijadikan sebagai 'other'. Untuk dapat melihatnya, penelitian ini akan menggunakan metode menyimak dan kemudian mengumpulkan data dari teks-teks yang diindikasikan sebagai satu bentuk tindakan penggambaran self dan other, selanjutnya teks dianalisis atas relasi-relasi yang terbentuk dan menciptakan satu gambaran menyeluruh terhadap ideologi, posisi, dan peran Orwell dalam laporan perjalananannya di Burma.

\section{Negosiasi dalam Burmese Days}

Di dalam karyanya yang dibuat setelah mengabdi sebagai British officer di Burma ini, Orwell tidak ingin bercerita tentang bagaimana pekerjaannya di sana, melainkan bercerita tentang suatu hal yang lebih kompleks, yakni tentang kehidupan orang-orang Inggris yang tinggal di Burma. Dalam Burmese Days, Orwell sebagai self berhati-hati di dalam menunjukkan siapa atau apa saja yang dibuatnya menjadi other, karena hal itu penting dalam menyampaikan makna terhadap pembaca. Seperti yang sudah diketahui bahwa Orwell merupakan seorang dengan paham humanisme universal yang menentang rasisme sehingga tercipta satu bentuk negosiasi dalam novel ini untuk menyuarakan pahamnya tersebut. Thompson (2011:119) menjelaskan bahwa "travelogues, then, usually offer a carefully staged presentation of the self. And for the desired image of the self to be maintained the travelogue must usually exercise a similar discrimination with regard to everything that is 'other' to the narratorial self: the places that the travellers visit, cultures that they encounter, and the individuals with whom they interact".

Negosiasi dapat dilihat melalui proses 'othering' yang dilakukan Orwell terhadap tiga hal tersebut di atas, yaitu tempat yang dikunjungi, budaya yang ditemui, dan orang-orang yang berinteraksi dengannya. Pertama perlu dilihat bagaimana Orwell menggambarkan Burma sebagai tempat yang dia kunjungi. Di dalam tulisan perjalanannya Orwell tidak langsung mengatakan ' $P$ ' tetapi dia berada di dalam tokoh utamanya yang bernama Flory, sehingga bisa dilihat bagaimana negosiasi Flory terhadap Burma. Sama seperti Orwell, Flory juga seseorang dari Inggris yang dikirim untuk bekerja di Burma oleh pemerintah Inggris. Flory, ketika baru datang di Burma, mengalami culture shock, hal yang biasa terjadi ketika ada perbedaan kebudayaan asal individu dengan lingkungan barunya. Orwell menggambarkan bagaimana Flory tidak terbiasa dengan Burma dikarenakan di sana dia harus menghilangkan kebiasaannya sebagai seorang Inggris. Hal ini terbukti dengan beberapa kali dia merasakan kerinduan dan akan bahagia apabila ada kesempatan untuk pergi ke Rangoon dimana dia bisa menikmati hidangan khas Inggris juga mendapatkan buku-buku terbitan Inggris yang dikirim ke Burma.

Kerinduan Flory akan Inggris ini sesungguhnya karena dia merasa tidak cocok dengan Burma sebagai tempat tinggalnya yang baru. Kemudian situasi seperti ini membawanya ke dalam sebuah pelarian diri dengan cara menyendiri dan tidak bergabung dengan kawankawannya sesama orang Inggris di Burma, dan lebih memilih menghabiskan waktu dengan membaca buku-buku terbitan Inggris "Flory took to reading voraciously and learned to live in books when life was tiresome" (Orwell, 1934:99).

Kutipan di atas belum menggambarkan posisi Orwell sepenuhnya, namun hal yang dapat ditangkap pada kutipan di atas yakni Orwell secara tak sadar mencoba memisahkan dirinya (self) dengan lingkungan di Burma 
(other). Dituliskan hal serupa di dalam biografi George Orwell sendiri mengenai kebiasaannya menyendiri 'In Burma, Blair (Orwell's real name) acquired a reputation as an outsider. He spent much of his time alone, reading" (Stansky \& Abrahams, 1994: 10). Hal ini tentu bertentangan dengan paham anti-rasisme, yang mana rasisme sendiri lahir karena adanya pemisahan, perbedaan antara warna kulit dan ras, dan di dalam antirasisme seharusnya dia sudah bisa membaur.

Kemudian yang kedua adalah bagaimana Orwell menggambarkan kebudayaan di Burma. Orwell membuka novelnya dengan menceritakan situasi politik di Kyauktada (nama tempat di Burma dimana Flory ditugaskan) yang mana klub berkumpulnya orang-orang Inggris di sana diharuskan memilih satu dari penduduk Kyauktada non-Inggris untuk menjadi anggota. Hal ini membuat pergolakan dari dua kubu, Inggris dan masyarakat Oriental. Dari kubu oriental sendiri diceritakan mengenai bagaimana seorang penduduk asli Burma yang bernama U Po Kyin yang sangat menginginkan untuk menjadi angggota klub agar dia bisa dihormati oleh penduduk lainnya. "to fight on the side of the British to become a parasite upon them had been his ruling ambition even as a child" (Orwell, 1934: 2).

Untuk hal itu Po Kyin merasa ada saingan, yaitu seorang dokter dari India bernama Veraswami. Po Kyin rela melakukan apa saja untuk mengalahkan sang dokter. Sementara dari sisi Inggris, mereka tidak menginginkan adanya orang selain Inggris yang masuk ke klub terutama yang terang-terangan menolaknya adalah Ellis, "we like to think there's still one place where we're free of them" (Orwell, 1934: 40).

Hal ini kemudian ditolak oleh Flory, sebagai bentuk anti-rasisme darinya. Akan tetapi, pada awalnya Flory tidak berani menyatakan pendapatnya secara langsung dan hanya bisa menghindari perbincangan mengenai pemilihan itu. Walaupun begitu, pada waktu yang tepat dia mengatakan bahwa dia akan mengajukan Veraswami sebagai anggota klub, "Flory stood up. He had got to say his say: "I propose dr. Veraswami as a member of this club" (Orwell, 1934:357).
Dari sini dapat dilihat bahwa Flory melakukan proses othering terhadap kebudayaan temanteman Inggrisnya yang melakukan rasisme.

Situasi politik di Kyauktada semakin memanas dikarenakan orang-orang Inggris masih berkeras untuk tidak memilih orang non-Inggris untuk menjadi anggotanya. Hal tersebut mengakibatkan persaingan antara Po Kyin dan Veraswami terus berlanjut. Ini buruk dikarenakan Po Kyin merupakan orang yang rela melakukan apa saja, "now let us go into this affair. We are going to make a concerted attack on dr. Veraswami. We are going to slander him, destroy his reputation and finally ruin him for ever. It will be rather a delicate operation" (Orwell, 1934:11). Dia rela menghasut penduduk setempat untuk kemudian melakukan gerakan nasionalisme dengan memberontak kepada Inggris dimana nantinya dia akan menjadi orang yang mendamaikan pemberontakan yang disulutnya sendiri agar dia mendapatkan simpati. Akan tetapi, politik adu domba dari Po Kyin tidak berhasil, dan justru membuat perselisihan antara Inggris dan penduduk setempat semakin menajam. Maxwell, salah seorang Inggris harus mati dikarenakan saat pemberontakan dia membunuh seorang pria yang dianggap berbahaya.

Dari dua hal di atas, bisa dilihat bahwa Flory mengalami dua kali othering di dalam kehidupannya di Burma. Pertama, dia melakukan othering terhadap rekan-rekan Inggrisnya yang melakukan tindak rasisme. Kemudian yang kedua, terhadap masyarakat asli Kyauktada yang diwakili oleh Po Kyin yang memiliki kebiasaan berpolitik yang begitu ekstrim sehingga menciptakan suasana yang mencekam.

Ketiga adalah bagaimana reaksi Flory terhadap orang-orang yang berinteraksi dengannya selama di Kyauktada (Burma). Flory selama di Burma berinteraksi dengan beberapa orang, di antaranya kawan-kawannya dari Inggris, dokter dari India yang bernama Veraswami, wanita lokal yang pernah menjadi simpanan Flory bernama Ma Hla May, dan Po Kyin melalui beberapa surat. Dari semua 
interaksinya, Flory kembali melakukan dua kali othering. Kepada kawan-kawannya yang sesama Inggris, dia melakukan othering dengan tidak setuju kepada mereka yang terlalu menjunjung prinsip 'pukka sahib', "There is a kind of spurious good-fellowship between The English. Its a tradition to booze together and swap meals and pretend to be friends though we all hate each other like poison. Like I hate their pukka sabib talk" (Orwell, 1934:54). Istilah itu sering digunakan oleh Flory untuk mengejek bagaimana orang-orang Inggris merasa dirinya sebagai yang paling tinggi dibandingkan orang-orang oriental. Istilah itu sendiri sebenarnyaberasal dari bahasa India yang berarti 'absolute' atau 'first class'.

Kemudian interaksi Flory dengan orang-orang Oriental, yang pertama adalah dokter Veraswami yang sangat dekat dengannya. Flory diceritakan nyaman bersahabat dengan sang dokter walaupun mereka berbeda ras. Diceritakan juga bahwa persahabatannya dengan sang dokter itulah yang membuat Flory tidak setuju dengan kawan-kawannya yang melakukan tindakan rasisme. Dokter ini, seperti orang oriental lainnya, tentu akan memuja orang-orang Inggris, dan dokter ini merupakan seorang yang memuja mereka tanpa tedeng aling-aling melainkan sungguh-sungguh dari hati. Bahkan dia saja selalu mendebat Flory yang selalu berpandangan jelek kepada sesama kawannya, "Can they make machinery, ships, railways, roads? They are belpless without you. What would happen to the Burmese forests if the English were not here? Instead of which, in your hands, actually they are improved" (Orwell, 1934:57).

Berbeda cerita dengan interaksinya dengan Veraswami, Flory merasa terancam dengan Po Kyin yang mulai mengirimkan suratsurat kaleng kepadanya. Po Kyin juga memuja Inggris tetapi dengan tujuan agar dia bisa mendapatkan jabatan yang tinggi, sehingga ini membuatnya menjadi ancaman, terutama bagi Flory yang dikenal sebagai teman dari Veraswami saingan dari Po Kyin. "to become a parasite upon the British had been Po Kyin's ruling ambition even as a child" (Orwell, 1934:2). Keinginannya itulah yang membuat dia kemudian rela melakukan apa saja. Terakhir adalah dengan Ma Hla May yang dijadikan sebagai 'mistress' oleh Flory yang pada akhirnya dicampakkan karena dia mulai menyukai wanita Inggris yang baru saja datang ke Kyauktada. Lebih dari itu, Flory merasa hubungannya dengan wanita Burma itu sebagai sebuah aib besar, terbukti dari ekspresi Flory ketika Ma Hla May datang di saat semua orang Inggris berkumpul dan mengungkapkan semuanya, 'Flory's face was ghastly. His face was yellow as bone and the sweat glistened on his forehed" (Orwell, 1934: 417). Di akhir cerita Flory bunuh diri karena tidak kuat menahan aib ditambah lagi wanita Inggris yang dicintainya tidak mau lagi berbicara dengannya karena masa lalu Flory dengan Ma Hla May.

\section{The 'I' dalam Burmese Days}

Tulisan perjalanan mempunyai ciri di dalam penulisannya yang menggunakan sudut pandang ' $T$. Hal ini dikatakan oleh Thompson (2011:65) bahwa 'first person verb forms often be found even in modes of travel writing that are otherwise very impersonal'. Sudut pandang ' $T$ ' yang ada di dalam Burmese Days diwakili oleh sudut pandang Flory.

Apabila sudah diketahui bahwa the ' $T$ ' di sini merupakan Flory yang juga adalah penulis itu sendiri, langkah selanjutnya adalah melihat lebih dalam siapa ' $T$. Oleh karena itu, harus ditentukan karakteristik ' $P$ ' dalam menuliskan kembali perjalanannya. Thompson membagi 'self ke dalam dua kategori, yaitu Cartesian dan Romantic travellers, yang mana keduanya memiliki karakteristik yang berbeda dalam menuliskan kembali perjalanannya.

"Enlightenment travellers priorotise factfinding and empirican enquiry into the wider world, and that they accordingly fashion themselves on the page principally as observers, and as Cartesian selves or subjectivities detached from the scene they survey. Romantic travellers, meanwhile, do not simply observe, they also react to the scenes, and record those reactions, and their reflections on them, in their accounts. In many cases, indeed, they seek out situations which arouse strong feelings and sensations or sublimity or spiritual intensity" (Thompson,2011:117). 
Orwell dikelompokkan ke dalam romantic traveller dikarenakan dalam penulisan Burmese Days adalah hasil pengamatan dan laporan perjalanan selama hidup di Burma disampaikan dengan model naratif deskriptif, penuh dengan kesan subjektivitas. Burmese Days juga merupakan petualangan Orwell dalam mencari ideologi politiknya. Tidak seperti novel alegorinya Animal Farm yang jelas memberikan kritik pada rezim Stalin, Burmese Days lebih menunjukkan 'in-betweeness' penulis (Stansky \& Abrahams, 1994:23). Hal itu kemudian dikaitkan dengan bagaimana di dalam proses othering Orwell melakukannya pada dua sisi .

Di dalam menanggapi rasisme yang dilakukan oleh kawan-kawannya, Orwell dikatakan memiliki paham kosmopolitan seperti yang dikatakan Thompson sebagai attitude encourages tolerance, understanding and a sense of global community (2011:6). Kosmopolitan sendiri berasal dari pengertian Kant 'ius cosmopolitanicum' di dalam esainya yang berjudul Perpetual Peace. Dikatakan bahwa kosmopolitan adalah guiding principle to protect people from war, and morally ground this cosmopolitan right by the principle of universal hospitality (Gregor, 1999: 329), sehingga apa yang diduga sebagai tindakan anti-rasisme yang dilakukan Orwell di dalam karyanya merupakan sebuah ketakutan akan hal buruk yang menimpa keberlangsungan kekuasaan Inggris di Burma. Hal itulah kenapa Orwell tidak hanya melakukan othering terhadap kawan-kawan Inggrisnya saja tetapi juga terhadap penduduk native dan cara berpolitik mereka yang menyeramkan.

Orwell menunjukkan bagaimana tindakan rasis yang dilakukan temantemannya yang menempatkan Inggris sebagai ras tertinggi di dalam kedudukan sosial itu membuat masyarakat yang termasuk ke dalam ras inferior sangat amat menginginkan kedudukan superior. Di saat ada kesempatan untuk bergabung bersama ras superior itu, persaingan terjadi di antara ras inferior, yanki antara Po Kyin dengan Veraswami. Kelompok Inggris yang tidak segera melakukan pemilihan dan masih ingin tetap mempertahankan superioritas mereka dengan tidak membiarkan native bergabung kemudian memberikan waktu untuk Po Kyin melancarkan berbagai macam cara untuk menjatuhkan Veraswami. Salah satunya adalah dengan menghasut penduduk asli untuk melakukan pemberontakan untuk kemerdekaan Burma dan menyebarkan berita tersebut sebelum pemberontakan terjadi kepada orang-orang Inggris dengan mengatasnamakan Veraswami.

"U Po Kyin had even sent one of his anonymous letters to Mrs. Lackersteen. Dr. Veraswami, the letter said was inciting the natives to abduct and rape the European women - no details were given, no were they needed. U Po Kyin had touched Mrs. Lackersteen's weak spot. To her the words 'sedition', 'Nationalism', 'rebellion', 'bomerule', conveyed one thing and one only that was the picture of herself being raped by a procession of jet-black coolies with rolling white eyebals" (Orwell, 1934: 2627).

Kemudian ketika pemberontakan benar-benar terjadi, Orwell membuatnya terlihat begitu mengerikan bagi Inggris dengan terbunuhnya salah satu dari mereka oleh para natives yang membalaskan dendam akan kematian saudaranya yang terbunuh oleh Maxwell, "It was the body of Maxwell cut almost to pieces with dabs by two relatives of the man whom he had shot" (Orwell, 1934:362). Orwell menunjukkan bahwa menjadikan native sebagai inferior dan melakukan tindakan rasisme bukanlah tindakan yang tepat agar kekuasaan Inggris tidak tergoyahkan di negara jajahannya, itulah kenapa dia menunjukkan sikap anti terhadap rasisme yang dilakukan teman-temannya. Seperti Sartre, Orwell hendak menunjukkan bahwa colonialism had to change in order to remain the same (2001:14) bukan lagi dengan menunjukkan sikap rasis terhadap penduduk asli. Karena ini berkaitan dengan keberlangsungan kekuasaan Inggris di Burma juga dengan Orwell yang ingin menunjukkan bahwa tindakan rasis hanya akan membawa kepada kesadaran nasionalisme penduduk yang akan menyebabkan munculnya pemberontakan, maka tentu saja Orwell 
menyuarakan anti-rasisme bukan tanpa maksud tertentu. Diaingin mengatakan mengenai bentuk kolonialisme baru atau neo-kolonialisme yang di dalamnya terdapat semangat kosmopolitan atau kesetaraan dan tidak lagi membedakan ras. Seperti yang dikatakan Sartre bahwa di dalam keberlangsungan kekuasaan, colonizer needed the natives to love them, like mothers in a way (2001:75).

Meskipun sama-sama lahir dan besar di negara penjajah, akan tetapi orang yang dari negara penjajah tinggal di wilyah jajahan memiliki psikologi yang berbeda dari yang hanya tinggal di negara aslinya dikarenakan mereka harus berinteraksi dengan kebudayaan, masyarakat, dan wilayah yang benar-benar berbeda (Jong, 2000: 20). Hal inilah kemudian yang membuat perbedaan pola pikir antara Inggris di wilayah jajahan dengan yang di Inggris. Contohnya saja di dalam novel Burmese Days, pemerintah Inggris dengan mudah mengeluarkan perintah untuk orang-orang Inggris di Burma untuk memilih satu penduduk asli untuk diajak bergabung ke dalam klub mereka. Hal itu tidak mudah diterima oleh orang Inggris di Burma yang sudah merasakan sendiri bagaimana hidup di tengah-tengah penduduk asli apalagi kemudian mereka diharuskan berkumpul di dalam klub, "Mr. Macgregor pursed his lips whimsicaly. He was in an awkward position, for the idea of electing a native member was not his own but had been passed on to him by the commissioner" (Orwell, 1934: 42).

Ketidaksetujuan akan perintah dari Inggris tidak ditunjukkan oleh Flory. Dia memilih sikap yang menurut terhadap perintah itu. Ini dikarenakan Flory yang lebih banyak menyendiri itu tidak benar-benar mengerti apa yang dirasakan oleh teman-temannya. Selain itu dia juga memiliki teman dekat seorang dokter dari India. Floryjuga lebih banyak menghabiskan waktunya untuk membaca buku yang dia bawa dari Inggris. Orwell bahkan menyebutkan nama penulis dari buku yang dibaca Flory, yaitu G. K. Chesterton, "he had sat down at the table and was reading G. K. Chesterton's" (Orwell, 1934: 30). Bacaan Flory inilah kemudian yang banyak mempengaruhi pola pikirnya yang berbeda dari teman-temannya. G. K. Chesterton sendiri dikenal sebagai penulis yang sangat besar pengaruhnya berkaitan dengan kekuasaan kolonial Inggris. Novelnya yang berjudul The Napoleon of The Nothing Hill menginsipirasi Michael Collins untuk memimpin perjuangan kemerdekaan bagi Irlandia. Kemudian esainya yang diterbitkan oleh Illustrated London News menginspirasi Mohandas Ghandi untuk memimpin pemberontakan pada pemerintah Inggris di India (Ker, 2011: 106). Bukan tidak mungkin dengan membaca karya-karya Chesterton, Flory sebagai seseorang yang berasal dari Inggris mulai mengkhawatirkan akan pemberontakan di Burma. Oleh karenya, dia tidak menyetujui adanya tindakan rasisme yang hanya akan mempercepat terjadinya pemberontakan.

\section{Kesimpulan}

Di dalam tulisan perjalanannya, Orwell ingin menunjukkan bahwa tindakan rasisme tidak akan berefek baik terhadap kekuasaan Inggris di Burma. Kemudian dia sendiri lebih memilih untuk melakukan tindakan anti-rasisme dengan cara menyetujui pemilihan penduduk asli untuk dijadikan anggota klub. Tindakan anti-rasisme yang ditunjukkan oleh Orwell di dalamnya sebenarnya merupakan sebuah tindakan kamuflase agar para penduduk tidak begitu merasa disisihkan sehingga mencegah pemberontakan kemerdekaan terjadi. Orwell tidak menuliskan tindakan anti-rasismenya sungguh-sungguh untuk membela ras yang dijadikan inferior, akan tetapi lebih kepada menunjukkan bahwa rasisme hanya akan mempercepat keruntuhan kekuasaan Inggris di Burma. Hal ini dapat dilihat dari bagaimana Orwell melakukan othering, sehingga tulisan perjalanan Orwell tersebut seakan menjelma sebagai buku panduan bagi pemerintah Inggris tentang bagaimana seharusnya politik kolonial dijalankan saat ini guna mengukuhkan kedudukan kolonialisme Inggris. Dari praktik Orwell dapat disimpulkan bahwa tindakan antirasisme yang ada dalam novel ini merupakan sebuah bentuk baru dari kolonialisme atau neokolonialisme. 


\section{Daftar Pustaka}

Gregor, Mary. 1999. Practical Philosophy: The Cambridge Edition of The Works of Immanuel Kant. Cambridge: Cambridge University Press.

Jong, Joop de. 2000. De Waaier Van Het Fortuin: De Nederlanders in Azie en de Indonesische Archipel. Deen Haag: SDU Uitgevers.

Ker, Ian (ed). 2011. G.K. Chesterton: A Biography. Oxford: Oxord University Press.

Newman, David. 2012. Sociology: Exploring The Architecture of Everyday Life. Los Angeles: SAGE.

Orwell, George. Burmese Days (Google Playbook).

Sartre, Jean Paul. 2001. Colonialism and Neocolonialism. Trans. Azzedine Haddour. London: Routledge.

Stansky, Peter\& William Abrahams. 1994. The Unknown Orwell and Orwell: The Transformation. California: Stanford University Press.

Thompson, Carl. 2011. Travel Writing. London: Routledge. 